\title{
Trend Analysis of Precipitation in Some Selected Stations in Anambra State
}

\author{
A. Ifeka, A. Akinbobola* \\ Department of Meteorology, Federal University of Technology, Akure, Nigeria \\ Email: aakinbobola@futa.edu.ng
}

Received 19 November 2014; revised 19 December 2014; accepted 28 December 2014

Academic Editor: Mohammad Valipour, University of Tehran, Iran

Copyright (C) 2015 by authors and Scientific Research Publishing Inc.

This work is licensed under the Creative Commons Attribution International License (CC BY). http://creativecommons.org/licenses/by/4.0/

(c) (i) Open Access

\section{Abstract}

State is in the South East geopolitical zone of Nigeria. The major occupation of the people in this region is trading and farming, which depends on rainfall and other climatic factors. This paper presents statistical and trend analyses of the rainfall in some selected stations in Anambra State, which includes Ifite-Ogwari, Awka, Onitsha and Ihiala. Rainfall data for a period of 1971-2010 were obtained from Climate Research Unit (CRU). The existence of trend and statistical analyses was conducted on monthly total rainfalls using non-parametric techniques. The study revealed that overall averages of yearly and monthly total rainfall were $5798.78 \mathrm{~mm}$ and $1739.62 \mathrm{~mm}$ in Ifite-Ogwari, 6051.8 $\mathrm{mm}$ and $1815 \mathrm{~mm}$ in Awka, $6288.87 \mathrm{~mm}$ and $1886.88 \mathrm{~mm}$ in Onitsha, and $6637.19 \mathrm{~mm}$ and $1997.1 \mathrm{~mm}$ in Ihiala. Yearly total rainfall has Mann-Whitney of 26 and 41 between 1971 and 1990, 1991 and 2010 respectively in Ifite-Ogwari, 32 and 42 between 1971 and 1990, 1991 and 2010 respectively in Awka, 42 and 39 between 1971 and 1990, 1991 and 2010 respectively in Onitsha, and 33 and 45 between 1971 and 1990, 1991 and 2010 respectively in Ihiala. These parameters show that there are significant trends in the rainfall in term of yearly total for the period. Sen's estimator revealed that there were significant downward trends for yearly total $(-0.775 \mathrm{~mm} / \mathrm{year})$ and (-0.094 mm/year) within the period of 1971-1990 and 1991-2010 in Ifite-Ogwari. There was an upward trend of yearly total $(1.841 \mathrm{~mm} /$ year) between 1971 and1990, whereas there was a downward trend of yearly total $(-0.211)$ between 1991 and 2010 in Awka. It was concluded that there was a significant downward trend in the yearly total and mean rainfalls in Ifite-Ogwari, Awka, Onitsha and Ihiala in the last four decades ( 40 years), which could be attributed to climate change.

\section{Keywords}

Precipitation, Trend Analysis, Non-Parametric Tests

\footnotetext{
${ }^{*}$ Corresponding author.
} 


\section{Introduction}

Trend detection is an active area of interest for both hydrology and climatology in order to investigate climate change scenarios and enhance climate impact research. Therefore, trend detection in precipitation time series is crucial for planning and designing regional water resources management. Several recent studies on climatologic trends conclude that trends in observed precipitation comprise a complex function of climatic environment, precipitation intensity and season [1] [2]. Relevant reviews on trend analysis in precipitation time series include the studies of [3]-[7].

The purpose of this work is to investigate the trend of total amount of rainfall in Ifite-Ogwari, Awka, Onitsha and Ihiala in Anambra State by detecting precipitation changes in the temporal structure for the period 1971-2010.

\section{Methodology}

\subsection{Study Area}

Anambra State of Nigeria was created on 27th August, 1991 out of the old Anambra State with its state capital as Awka and lies at Latitude $6^{\circ} 20^{\prime} \mathrm{N}$ and Longitude $7^{\circ} 00^{\prime} \mathrm{E}$. The land area is approximately $4844 \mathrm{~km}^{2}$, its annual population growth rate of $2.21 \%$ per annum [8]. Anambra State has over $60 \%$ of its people living in urban areas making it one of the most urbanized places in Nigeria [9]. Since then, the state has being witnessing immense growth in the size of built-up areas, number of immigrants, transportation and commercial activities. It experiences warm humid tropical climate, with average rainfall between 1520 and $2020 \mathrm{~mm}$ per annum. Minimum and Maximum temperatures range between $25.4^{\circ} \mathrm{C}$ and $30.6^{\circ} \mathrm{C}$ and its vegetation is the tropical forest type [10].

For this study, the following towns were selected; they are Awka, Onitsha, Ihiala and Ifite-Ogwari. Awka lies between $6^{\circ} 21^{\prime} \mathrm{N}$ and $7^{\circ} 61^{\prime} \mathrm{E}$, Onitsha lies between $6^{\circ} 17^{\prime} \mathrm{N}$ and $6^{\circ} 78^{\prime} \mathrm{E}$, Ihiala lies between $5^{\circ} 86^{\prime} \mathrm{N}$ and $6^{\circ} 86^{\prime} \mathrm{E}$ and Ifite-Ogwari lies between $6^{\circ} 60^{\prime} \mathrm{N}$ and $6^{\circ} 95^{\prime} \mathrm{E}$ (Figure 1).

\subsection{Materials and Methods}

The data used in this study include the records of the precipitation obtained from Climatic Research Unit (CRU). The precipitation records includes reanalysis observation spanning from 1971 to 2010 and cover a period of 40 years, which is considered to be long enough for a valid mean statistic [11]. Moreover, [12] states that a minimum record length of 25 years ensures statistical validity of the trend results in climate change research.

Statistical tools commonly used to detect significant trends in climatic and hydrological time series is either or the non-parametric test such as Mann-Whitney U, Wilcoxon W, Mann-Kendall or Spearman's rank correlation and the parametric test such as student's t-test [13] [14]. The non-parametric test is considered better because it is a function of the ranks of observation and it displays much insensitivity to outliers unlike the parametric counterpart. Slope $(S)$ of the existence trend were determined using Sen's estimator and overall slopes (Tan $(\beta+\alpha+\varphi)$ were computed as follows:

$$
\begin{aligned}
& S=\frac{R_{A}-R_{B}}{N_{A}-N_{B}} \text { where, } R_{A}=\text { rank of group } A \\
& R_{B}=\text { rank of group } B \\
& N_{A}=\text { number of samples in group } A
\end{aligned}
$$

$$
N_{B}=\text { number of samples in group } B
$$

$$
\operatorname{Tan}(\alpha+\beta+\varphi)=\frac{\operatorname{Tan} \alpha+\frac{\operatorname{Tan} \beta+\operatorname{Tan} \varphi}{1-\operatorname{Tan} \beta * \operatorname{Tan} \varphi}}{1-\operatorname{Tan} \alpha+\frac{\operatorname{Tan} \beta+\operatorname{Tan} \varphi}{1-\operatorname{Tan} \beta * \operatorname{Tan} \varphi}}
$$

where, $\operatorname{Tan}(\alpha)=$ slope of group $A$

$$
\begin{aligned}
& \operatorname{Tan}(\beta)=\text { slope of group } B \\
& \operatorname{Tan}(\varphi)=\text { slope of group } C \\
& \alpha=\text { angle of group } A
\end{aligned}
$$




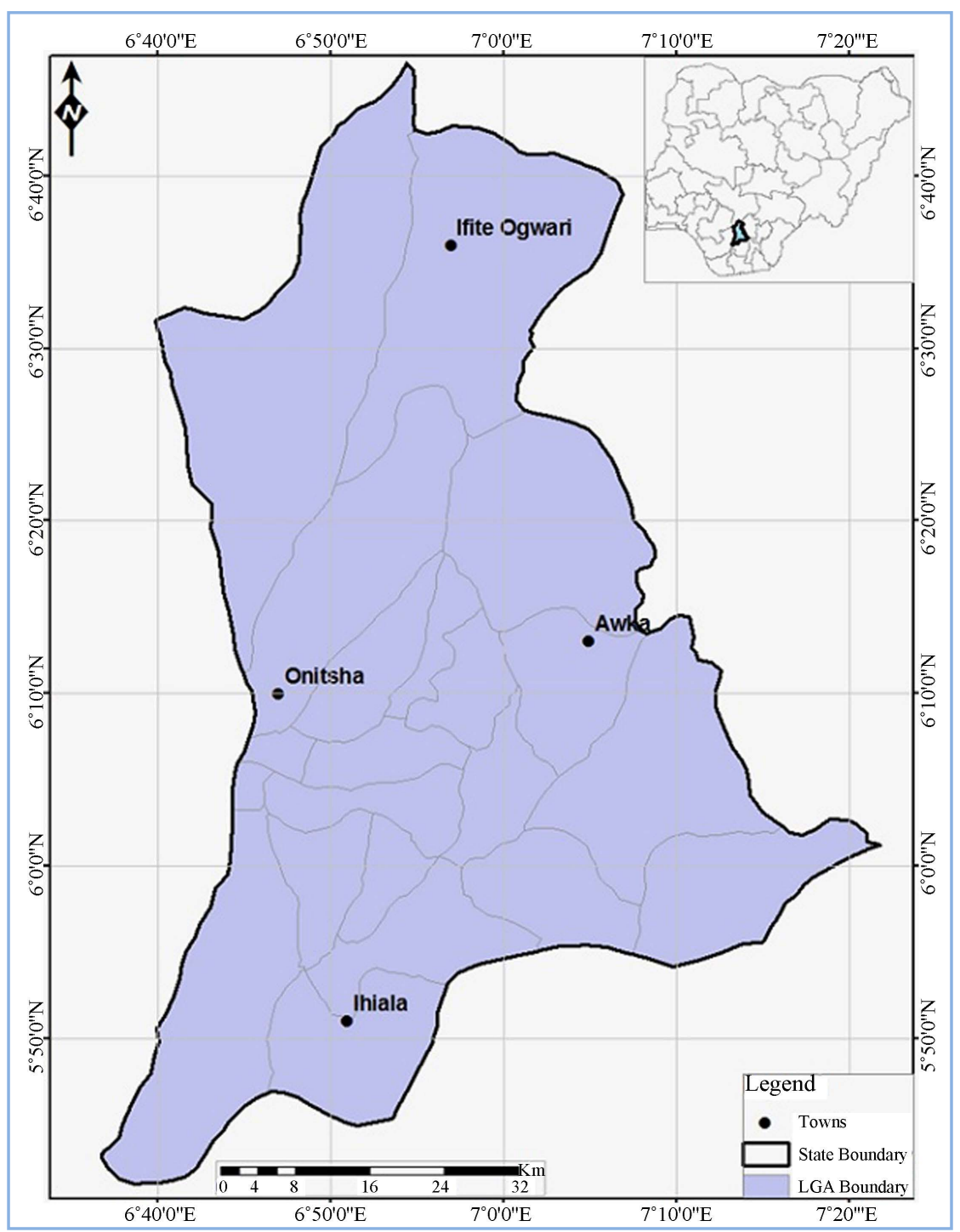

Figure 1. Map of anambra State showing the selected stations.

$\beta=$ angle of group $B$

$$
\varphi=\text { angle of group } C
$$

Mann-Whitney $U$-test

$$
\begin{gathered}
U_{x}=n_{x} n_{y}+\left(\left(n_{x}\left(n_{x}+1\right)\right) / 2\right)-R_{x} \\
U_{x}=n_{x} n_{y}+\left(\left(n_{y}\left(n_{y}+1\right)\right) / 2\right)-R_{y}
\end{gathered}
$$

Where, $n_{x}$ is the number of observations in the first group, $n_{y}$ is the number of observations in the second group, $R_{x}$ is the sum of the ranks assigned to the first group and $R_{y}$ is the sum of the ranks assigned to the second group. In other words, both $(U)$ equations can be understood as the number of times observation in one sample precede or follow observation in the other sample.

Wilcoxon Rank Sum Test

$$
z_{T}=\frac{T-\mu_{T}}{\sigma_{T}}
$$


Where, $\mu_{T}=\frac{N(n+1)}{4}$

$$
\sigma_{T}=\sqrt{\frac{n(n+1)(2 n+1)}{24}}
$$

$n=$ sample size

$T=$ sum of ranks for smaller sample size $\left(n_{1}\right)$

$n_{1}=$ smaller of sample sizes

$n_{2}=$ larger of sample sizes

$n_{1} \geq 10$ and $n_{2} \geq 10$

Sen's Slope Estimator Test: The magnitude of trend is predicted by Sen's estimator.

Here, the slope $\left(T_{i}\right)$ of all data pairs is computed as [15]

$$
T_{i}=\frac{x_{j}-x_{k}}{j-k} \quad \text { for } i=1,2, \cdots, N
$$

where $x_{j}$ and $x_{k}$ are considered as data values at time $j$ and $k \quad(j>k)$ corresponding. The median of these $N$ values of $T_{i}$ represented as Sen's estimator of slope which is given as:

$$
\begin{aligned}
Q_{i} & =\left\{\frac{1}{2}\left(T_{\frac{N}{2}}+T_{\frac{N+2}{2}}\right)--N\right. \text { is odd } \\
Q_{i} & =\left\{\frac{1}{2}\left(T_{\frac{N+1}{2}}\right)--N\right. \text { is even }
\end{aligned}
$$

Sen's estimator is computed as $Q_{i}=\left\{\frac{1}{2}\left(T_{\frac{N}{2}}+T_{\frac{N+2}{2}}\right)\right.$ if $N$ appears odd, and it is considered as $Q_{i}=\left\{\frac{1}{2}\left(T_{\frac{N+1}{2}}\right)\right.$ if $N$ appears even. At the end, $Q_{i}$ is computed by a two sided test at $100(1-\alpha) \%$ confidence interval and then a true slope can be obtained by the non-parametric test. Positive value of $Q_{i}$ indicates an upward or increasing trend and a negative value of $Q_{i}$ gives a downward or decreasing trend in the time series.

Models that relate yearly total rainfall to the year were developed from the trend analysis using Statistical and logical techniques.

\section{Results and Discussion}

Results of this study are discussed in the following categories: statistical summary of rainfall (annual mean precipitation); monthly rainfall trend and sequential analyses.

\subsection{Statistical Monthly Rainfall Summary}

\subsubsection{Ifite-Ogwari}

Table 1 presents monthly mean, median, maximum and minimum rainfalls in Ifite-Ogwari. The table revealed that the rainy period is between February and November, with May, June, July, August, September and October as significant rainy months. The month August has the highest magnitude of monthly rainfall with $597 \mathrm{~mm}$ followed by month September with $573 \mathrm{~mm}$. This shows that for farming activities in rainy seasons crops with maximum water demands month of six months are best situated for the station.

\subsubsection{Awka}

Table 2 presents monthly mean, median, maximum and minimum rainfalls in Awka. The table showed the rainy period is between March and October, with April, May, June, July, August, September and October as signifi- 
Table 1. Statistical summary of monthly rainfall in Ifite-Ogwari.

\begin{tabular}{ccccccccccccc}
\hline Months & January & February & March & April & May & June & July & Aug. & Sept. & Oct. & Nov. & Dec. \\
\hline Mean & 6.18 & 23.2 & 70.15 & 132.9 & 203.16 & 230.25 & 277 & 250.9 & 292.2 & 209.5 & 35.91 & 8.27 \\
Maximum & 30.9 & 107.1 & 205 & 286.5 & 376.1 & 330.7 & 423.7 & 597.9 & 573.6 & 336.9 & 163.5 & 53.9 \\
Minimum & 0 & 0 & 14.6 & 43.6 & 128.5 & 137.1 & 144.7 & 89.8 & 187.2 & 60.4 & 0 & 0 \\
Median & 3.45 & 17.25 & 59.2 & 122.35 & 193.8 & 231.35 & 271.1 & 219.8 & 287.1 & 208.3 & 31.4 & 4.65 \\
$\begin{array}{c}\text { Standard } \\
\text { Deviation }\end{array}$ & 8.64 & 24.04 & 43.27 & 55.42 & 51.47 & 39.63 & 75.5 & 111.1 & 72.8 & 68.6 & 35.79 & 11.4 \\
$\begin{array}{c}\text { Coefficient of } \\
\text { Variation }\end{array}$ & 139.8 & 103.65 & 61.69 & 41.7 & 25.34 & 17.21 & 27.24 & 44.28 & 24.93 & 32.74 & 99.66 & 137.85 \\
\hline
\end{tabular}

Table 2. Statistical summary of monthly rainfall in Awka.

\begin{tabular}{ccccccccccccc}
\hline Months & January & February & March & April & May & June & July & Aug. & Sept. & Oct. & Nov. & Dec. \\
\hline Mean & 7.04 & 16.87 & 71.2 & 147.61 & 209.4 & 239.7 & 292.6 & 266 & 298.4 & 217.5 & 40.59 & 8.64 \\
Maximum & 51.3 & 94.9 & 222.3 & 331.2 & 403.1 & 392.2 & 587.7 & 487.8 & 582.7 & 345.6 & 179.9 & 50.4 \\
Minimum & 0 & 0 & 7.3 & 26.7 & 96.2 & 90.2 & 113.1 & 88.5 & 152.3 & 64.6 & 0 & 0 \\
Median & 2.45 & 13 & 65.4 & 145.3 & 202.9 & 236.4 & 293.5 & 245.9 & 286.1 & 218.2 & 24.5 & 2.35 \\
$\begin{array}{c}\text { Standard } \\
\text { Deviation }\end{array}$ & 12.12 & 19.33 & 48.97 & 58.72 & 66.3 & 63.7 & 95.5 & 112.3 & 82.5 & 74.7 & 47.31 & 13.1 \\
$\begin{array}{c}\text { Coefficient of } \\
\text { Variation }\end{array}$ & 172.26 & 114.59 & 68.78 & 39.78 & 31.68 & 26.56 & 32.63 & 42.23 & 27.66 & 34.36 & 116.6 & 151.54 \\
\hline
\end{tabular}

cant rainy months. The month of July has the highest magnitude of monthly rainfall with $587.7 \mathrm{~mm}$ followed by month September with $582.7 \mathrm{~mm}$.

\subsubsection{Onitsha}

Table 3 presents monthly mean, median, maximum and minimum rainfalls in Onitsha. The table revealed that the rainy period is February and September, with March, April, May, June, July, August and September as significant rainy months. The month of September has the highest magnitude of monthly rainfall with $615.6 \mathrm{~mm}$ followed by month August with $535.2 \mathrm{~mm}$.

\subsubsection{Ihiala}

Table 4 presents monthly mean, median, maximum and minimum rainfalls in Ihiala. The table showed that the rainy period is March and October, with April, May, June, July, August, September and October as significant rainy months. The month of September has the highest magnitude of monthly rainfall with $648 \mathrm{~mm}$ followed by month of July with $536.7 \mathrm{~mm}$.

\subsubsection{Trend Analysis}

The result of trend analyses are discussed in the following ways: trend of yearly rainfalls with the sequences of the monthly and yearly rainfalls.

\subsection{Ifite-Ogwari}

\subsubsection{Trend of Yearly Rainfalls}

Table 5 presents results of non-parametric analyses (mean rank, Mann-Whitney, Wilcoxon, standard anomaly index (SAI:Z), Asymptotic Significant, Sen's estimator. From these analyses presented in the table, it was observed that they are downward trend in the total, mean, maximum and minimum rainfall in Ifite-Ogwari between 1971 and 1990, but these trends were not statistically significant at 95\% confidence level. Between 1991 and 2010, there are downward trends in the rainfall parameters with SAI's of -1.814 and -0.680 for between 1991 
Table 3. Statistical summary of monthly rainfall in Onitsha.

\begin{tabular}{ccccccccccccc}
\hline Months & January & February & March & April & May & June & July & Aug. & Sept. & Oct. & Nov. & Dec. \\
\hline Mean & 8.38 & 23.37 & 78.59 & 151.6 & 215.6 & 244.88 & 299.8 & 267.3 & 309.9 & 228 & 48.25 & 11.01 \\
Maximum & 58 & 131.8 & 215.7 & 352.6 & 434.3 & 385 & 524.8 & 535.2 & 615.6 & 359.5 & 257 & 62.9 \\
Minimum & 0 & 0 & 10.3 & 15.3 & 119.1 & 100.8 & 115.2 & 100.7 & 188.1 & 34.2 & 0 & 0 \\
Median & 4.85 & 19.8 & 69.05 & 137.4 & 208.3 & 242.85 & 304 & 230.6 & 311.1 & 228.9 & 34.65 & 4.7 \\
$\begin{array}{c}\text { Standard } \\
\text { Deviation }\end{array}$ & 13.36 & 24.48 & 48.29 & 64.1 & 63.8 & 54.1 & 93.1 & 113.6 & 80.3 & 75.4 & 53.29 & 15.25 \\
$\begin{array}{c}\text { Coefficient of } \\
\text { Variation }\end{array}$ & 159.38 & 104.74 & 61.44 & 42.3 & 29.59 & 22.09 & 31.06 & 42.51 & 25.91 & 33.05 & 110.4 & 138.44 \\
\hline
\end{tabular}

Table 4. Statistical summary of monthly rainfall in Ihiala.

\begin{tabular}{|c|c|c|c|c|c|c|c|c|c|c|c|c|}
\hline Months & January & February & March & April & May & June & July & Aug. & Sept. & Oct. & Nov. & Dec. \\
\hline Mean & 12.7 & 28.94 & 91.55 & 161.18 & 223.55 & 258.14 & 314.5 & 265.9 & 321.3 & 244.4 & 59.22 & 15.72 \\
\hline Maximum & 86.6 & 154.7 & 226.9 & 352.3 & 391.7 & 440.2 & 536.7 & 527.6 & 648 & 414 & 289 & 74.9 \\
\hline Minimum & 0 & 1.3 & 14.4 & 31.7 & 129.5 & 118.7 & 140.7 & 94.1 & 203.9 & 50.6 & 0.4 & 0 \\
\hline Median & 7.15 & 25 & 86.25 & 155.05 & 219.65 & 246.9 & 317.9 & 254.5 & 318.3 & 241.7 & 47 & 9.35 \\
\hline $\begin{array}{l}\text { Standard } \\
\text { Deviation }\end{array}$ & 17.69 & 27.99 & 47 & 58.54 & 62.24 & 62.64 & 102.1 & 105.5 & 85.8 & 82.6 & 53.67 & 19.15 \\
\hline $\begin{array}{l}\text { Coefficient of } \\
\text { Variation }\end{array}$ & 139.31 & 96.7 & 51.34 & 36.32 & 27.84 & 24.27 & 32.47 & 39.68 & 26.72 & 33.81 & 90.63 & 121.81 \\
\hline
\end{tabular}

Table 5. Non-parameter test of summarized statistical data in Ifite-Ogwari.

\begin{tabular}{ccccccc}
\hline Year & Mean & $\begin{array}{c}\text { Mann-Whitney } \\
\mathbf{U}\end{array}$ & Wilcoxon & Z-Statistics & $\begin{array}{c}\text { Asymptotic } \\
\text { Significant } \\
\text { (2 Tailed) }\end{array}$ & $\begin{array}{c}\text { Sen's } \\
\text { Estimator }\end{array}$ \\
\hline $\mathbf{1 9 7 1 - 1 9 8 0}$ & 12.9 & 26 & 81 & -1.814 & 0.070 & -0.775 \\
Samples & & & 10 \\
$\mathbf{1 9 8 1 - 1 9 9 0}$ & 8.1 & & & -0.680 & 0.496 & -0.094 \\
$\mathbf{1 9 9 1 - 2 0 0 0}$ & 11.4 & 41 & 96 & & 10 \\
\hline $\mathbf{2 0 0 1 - 2 0 1 0}$ & 9.6 & & & & \\
\hline
\end{tabular}

and 2010. Asymptotic significant (probability) of these rainfall parameters were found to be 0.070 and 0.496 for these periods respectively. SAI provides an area average index of relation rainfall yields based on the standard of total, mean, maximum and minimum rainfalls. These magnitudes of SAI $(Z>1.96)$ and probabilities show that the downward trends are statistically significant at $95 \%$ confidence level. Also the sign $(Z<0)$ revealed that the values were less than expected overall mean rainfall and that there was more dryness in the period between 1971 and 1990 than the period between 1991 and 2010.

Sen's estimator revealed that yearly total rainfalls have trends of $-0.775 \mathrm{~mm} / \mathrm{year}$ and $-0.094 \mathrm{~mm} /$ year for a period of 1971-1990 and 1991-2010 respectively.

\subsubsection{Sequence Analysis of the Rainfalls}

Figures 2(a)-(d) present sequential values of the rainfalls in Ifite-Ogwari. The figures apparently show decreasing trends in rainfalls.

Figures 2(a)-(d) illustrate the downward trends appearance of the yearly total, maximum, minimum and mean rainfall. From the graphs, it appears the strongest decreasing trend occurred between 1979 and 1986.

Figure 2(c) clearly shows yearly maximum rainfall from 1971 to 2010 which implies that 1987 and 2004 recorded highest magnitude of rainfall with $579.9 \mathrm{~mm}$ and $573.6 \mathrm{~mm}$ respectively. These trends can be attributed to 


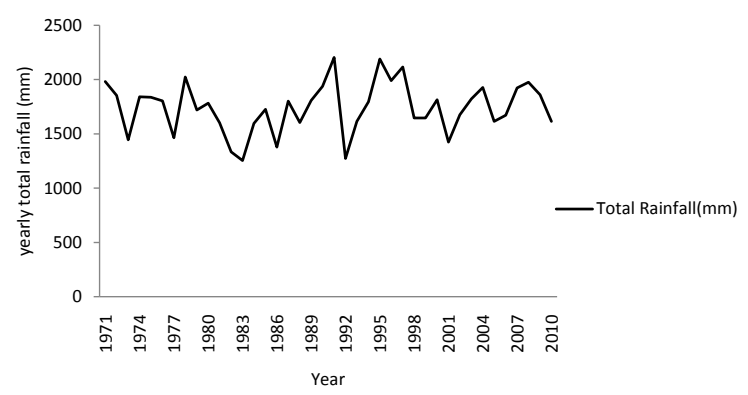

(a)

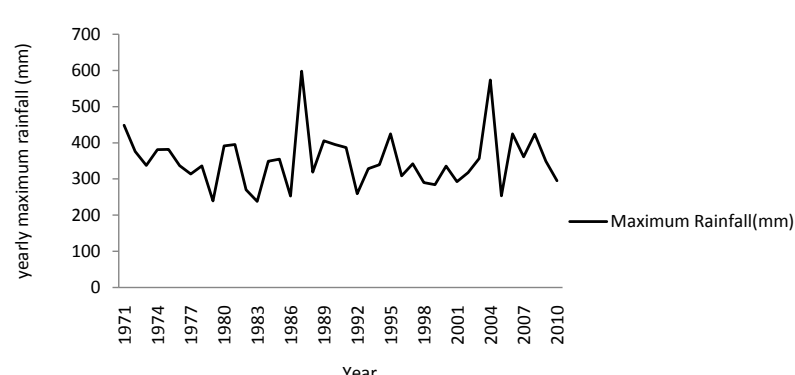

(c)

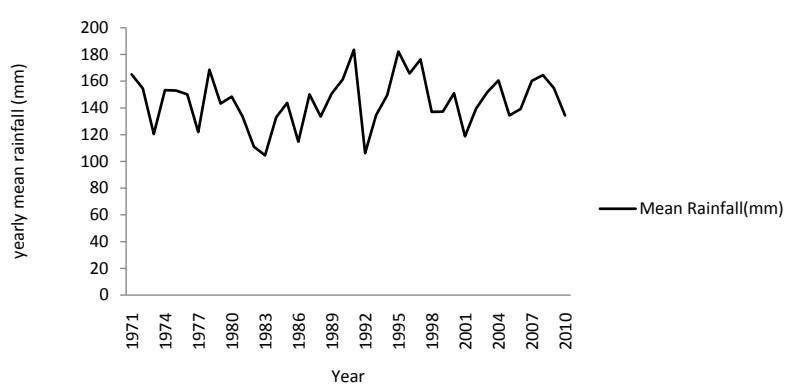

(b)

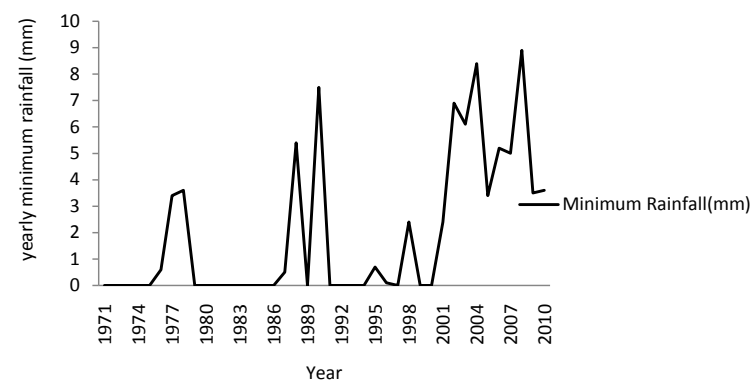

(d)

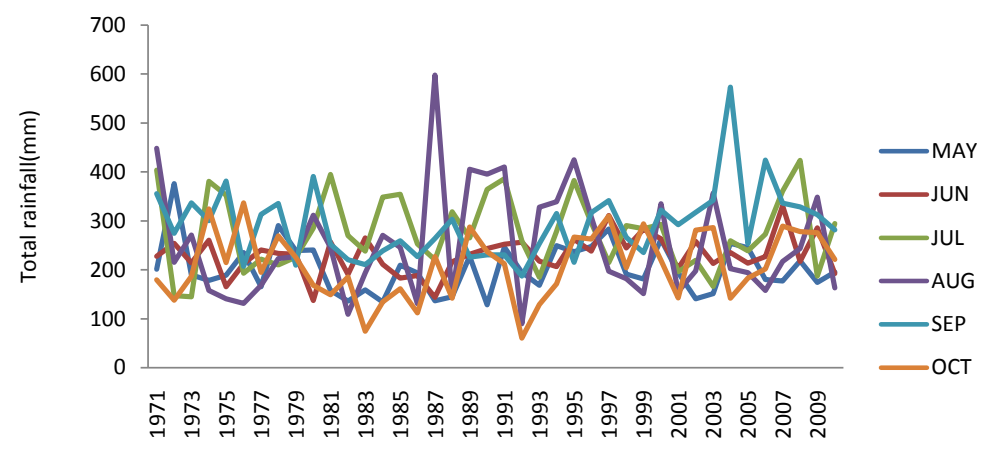

Year

(e)

Figure 2. (a)-(d) Sequence of yearly total rainfall in Ifite-Ogwari; (e) Sequence of rainfall in the month of May, June, July, August, September and October from 1971 to 2010 in Ifite-Ogwari.

climate change, which manifest itself in the area as temperature is increasing and reduction in rainfall in the years 1971-1974, 1980-1985 and 1991-1994 as showed in Figure 2(d).

Figure 2(e) clearly shows the month of August in 1987 recorded the highest magnitude of rainfall with 597.9 $\mathrm{mm}$ followed by the month of September in 2004 with $573.6 \mathrm{~mm}$ of rainfall amounts. The month of October in 1992 recorded the lowest magnitude of rainfall with $60.44 \mathrm{~mm}$.

\subsection{Awka}

\subsubsection{Trend of Yearly Rainfalls}

Table 6 presents results of non-parametric analyses (mean rank, Mann-Whitney, Wilcoxon, standard anomaly index (SAI:Z), Asymptotic Significant, Sen's estimator. From these analyses presented in the table, it was observed that they are upward trend in the total, mean, maximum and minimum rainfall in Awka between 1971 and 1990, but these trends were not statistically significant at 95\% confidence level. Between 1991 and 2010, there are downward trends in the rainfall parameters with SAI's of -1.361 and -0.605 for between 1991 and 2010. Asymptotic significant (probability) of these rainfall parameters were found to be 0.174 and 0.545 for these periods respectively. SAI provides an area average index of relation rainfall yields based on the standard 
Table 6. Non-parameter test of summarized statistical data in Awka.

\begin{tabular}{cccccccc}
\hline Year & Mean & Mann-Whitney U & Wilcoxon & Z-Statistics & $\begin{array}{c}\text { Asymptotic } \\
\text { Significant } \\
\text { (2 Tailed) }\end{array}$ & Sen's Estimator Number of Samples \\
\hline $\mathbf{1 9 7 1 - 1 9 8 0}$ & 8.7 & & & & & & 10 \\
$\mathbf{1 9 8 1 - 1 9 9 0}$ & 12.3 & 32 & 87 & -1.361 & 0.174 & 1.841 & 10 \\
$\mathbf{1 9 9 1 - 2 0 0 0}$ & 11.3 & & & & & 10 \\
$\mathbf{2 0 0 1 - 2 0 1 0}$ & 9.7 & 42 & 97 & -0.605 & 0.545 & -0.211 & 10 \\
\hline
\end{tabular}

of total, mean, maximum and minimum rainfalls. These magnitude of SAI $(Z>1.96)$ and probabilities show that the downward trends are statistically significant at $95 \%$ confidence level. Also the sign $(Z<0)$ revealed that the values were more than expected overall mean rainfall and that there was more wetness in the period between 1971 and 1990 than the period between 1991 and 2010.

Sen's estimator revealed that yearly total rainfalls have trends of $1.841 \mathrm{~mm} /$ year and $-0.211 \mathrm{~mm} / \mathrm{year}$ for a period of 1971-1990 and 1991-2010 respectively.

\subsubsection{Sequence Analysis of the Rainfalls}

Figures 3(a)-(d) present sequential values of the rainfalls in Awka. The figures apparently show decreasing trends in rainfalls.

Figures 3(a)-(d) illustrate the downward trends appearance of the yearly total, maximum, minimum and mean rainfall. From the graphs, it appears the strongest decreasing trend occurred between 1979 and 1983 .

Figure 3(c) clearly shows yearly maximum rainfall from 1971 to 2010 which implies that 1990 and 2004 recorded highest magnitude of rainfall with $587.7 \mathrm{~mm}$ and $582.7 \mathrm{~mm}$ respectively. These trends can be attributed to climate change, which manifest itself in the area as temperature is increasing and reduction in rainfall in the years 1971-1975, 1979-1983 and 1991-1992 as showed in Figure 3(d).

Figure 3(e) clearly shows the month of July in 1990 recorded the highest magnitude of rainfall with 587.7 $\mathrm{mm}$ followed by the month of September in 2004 with $582.7 \mathrm{~mm}$ of rainfall amounts. The month of October in 1983 recorded the lowest magnitude of rainfall with $64.6 \mathrm{~mm}$.

\subsection{Onitsha}

\subsubsection{Trend of Yearly Rainfalls}

Table 7 presents results of non-parametric analyses (mean rank, Mann-Whitney, Wilcoxon, standard anomaly index (SAI:Z), Asymptotic Significant, Sen's estimator. From these analyses presented in the table, it was observed that they are upward trend in the total, mean, maximum and minimum rainfall in Onitsha between 1971 and 1990, but these trends were not statistically significant at 95\% confidence level. Between 1991 and 2010, there are downward trends in the rainfall parameters with SAI's of -0.605 and -0.832 for between 1991 and 2010. Asymptotic significant (probability) of these rainfall parameters were found to be -0.545 and -0.406 for these periods respectively. SAI provides an area average index of relation rainfall yields based on the standard of total, mean, maximum and minimum rainfalls. These magnitudes of SAI $(Z>1.96)$ and probabilities show that the downward trends are statistically significant at $95 \%$ confidence level. Also the sign $(Z<0)$ revealed that the values were more than expected overall mean rainfall and that there was more wetness in the period between 1971 and 1990 than the period between 1991 and 2010.

Sen's estimator revealed that yearly total rainfalls have trends of $0.146 \mathrm{~mm} /$ year and $0.535 \mathrm{~mm} /$ year for a period of 1971-1990 and 1991-2010 respectively.

\subsubsection{Sequence Analysis of the Rainfalls}

Figures 4(a)-(d) present sequential values of the rainfalls in Onitsha. The figures apparently show decreasing trends in rainfalls.

Figures 4(a)-(d) illustrate the downward trends appearance of the yearly total, maximum, minimum and mean rainfall. From the graphs, it appears the strongest decreasing trend occurred between 1979 and 1983.

Figure 4(c) clearly shows yearly maximum rainfall from 1971 to 2010 which implies that 1990 and 2004 rec- 


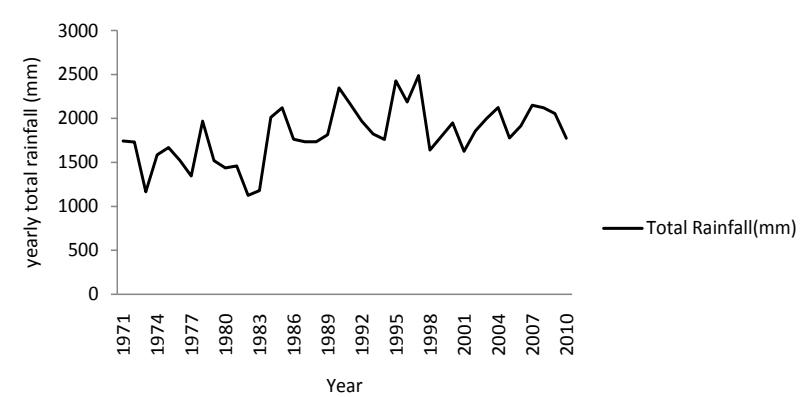

(a)

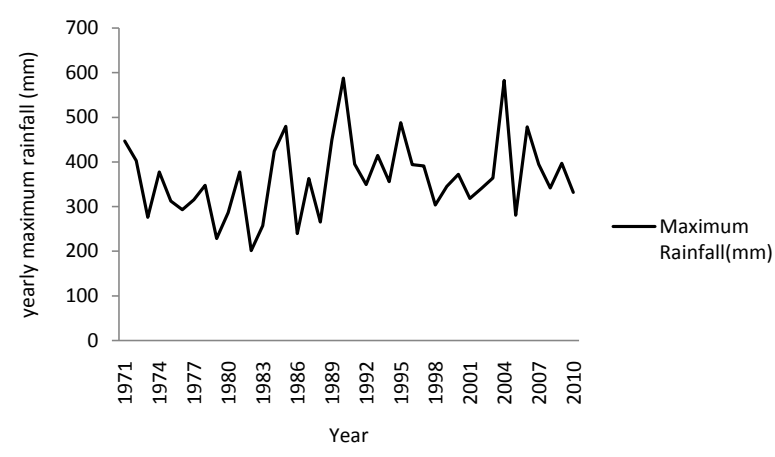

(c)

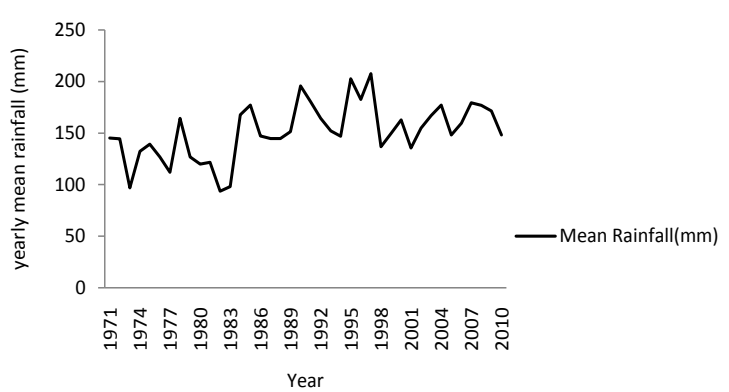

(b)

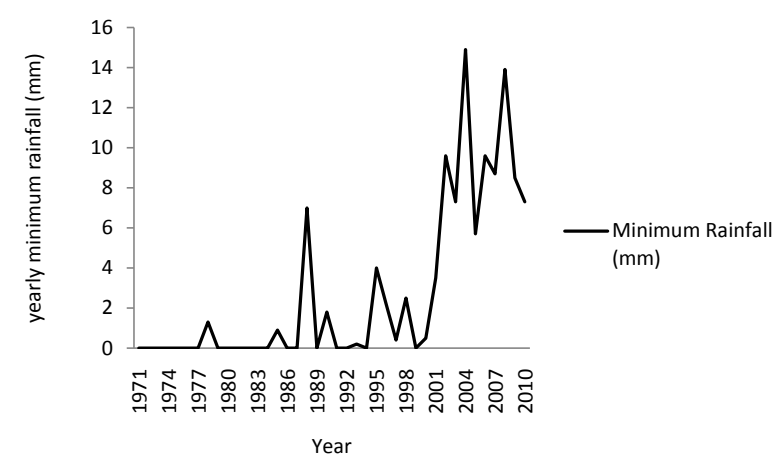

(d)

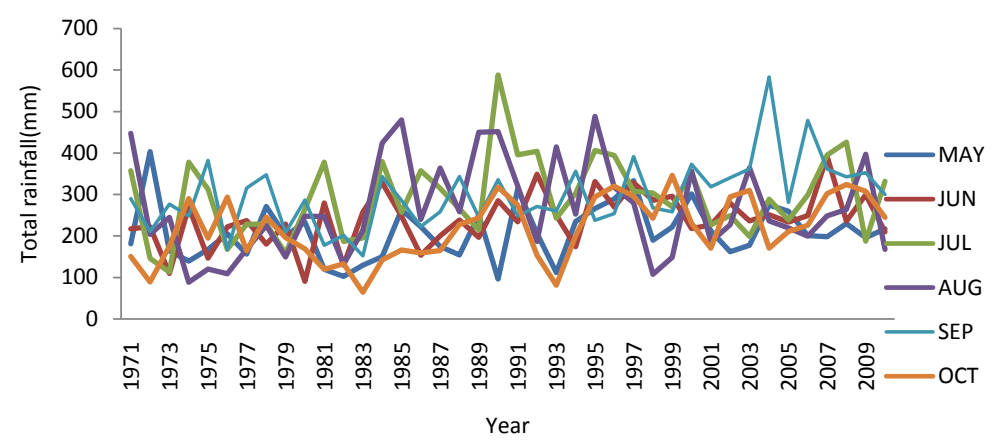

(e)

Figure 3. (a)-(d) Sequence of yearly minimum rainfall in Awka; (e) Sequence of rainfall in the month of May, June, July, August, September and October from 1971 to 2010 in Awka.

Table 7. Non-parameter test of summarized statistical data in Onitsha.

\begin{tabular}{|c|c|c|c|c|c|c|c|}
\hline Year & Mean & Mann-Whitney U & Wilcoxon & $Z$-Statistics & $\begin{array}{l}\text { Asymptotic } \\
\text { Significant } \\
\text { (2 Tailed) }\end{array}$ & Sen's Estimator & Number of Samples \\
\hline 1971-1980 & 11.3 & & & & & & 10 \\
\hline 1981-1990 & 9.7 & 42 & 97 & -0.605 & -0.545 & 0.146 & 10 \\
\hline 1991-2000 & 11.6 & & & & & & 10 \\
\hline 2001-2010 & 9.4 & 39 & 94 & -0.832 & -0.406 & -0.535 & 10 \\
\hline
\end{tabular}

orded highest magnitude of rainfall with $524.8 \mathrm{~mm}$ and $615.6 \mathrm{~mm}$ respectively. These trends can be attributed to climate change, which manifest itself in the area as temperature is increasing and reduction in rainfall in the years 1971-1977, 1979-1984 and 1991-1994 as showed in Figure 4(d).

Figure 4(e) clearly shows the month of September in 2004 recorded the highest magnitude of rainfall with $615.6 \mathrm{~mm}$ followed by the month of August in 1971 with $535.2 \mathrm{~mm}$ of rainfall amounts. The month of October in 1983 recorded the lowest magnitude of rainfall with $34.2 \mathrm{~mm}$. 


\subsection{Ihiala}

\subsubsection{Trend of Yearly Rainfalls}

Table 8 presents results of non-parametric analyses (mean rank, Mann-Whitney, Wilcoxon, standard anomaly index (SAI:Z), Asymptotic Significant, Sen's estimator. From these analyses presented in the table, it was observed that they are upward trend in the total, mean, maximum and minimum rainfall in Ihiala between 1971 and 1990, but these trends were not statistically significant at 95\% confidence level. Between 1991 and 2010, there are downward trends in the rainfall parameters with SAI's of -1.285 and -0.378 for between 1991 and 2010 . Asymptotic significant (probability) of these rainfall parameters were found to be 0.199 and 0.705 for these periods respectively. SAI provides an area average index of relation rainfall yields based on the standard of total, mean, maximum and minimum rainfalls. These magnitudes of SAI $(Z>1.96)$ and probabilities show that the downward trends are statistically significant at $95 \%$ confidence level. Also the sign $(Z<0)$ revealed that the values were more than expected overall mean rainfall and that there was more wetness in the period between 1971 and 1990 than the period between 1991 and 2010.

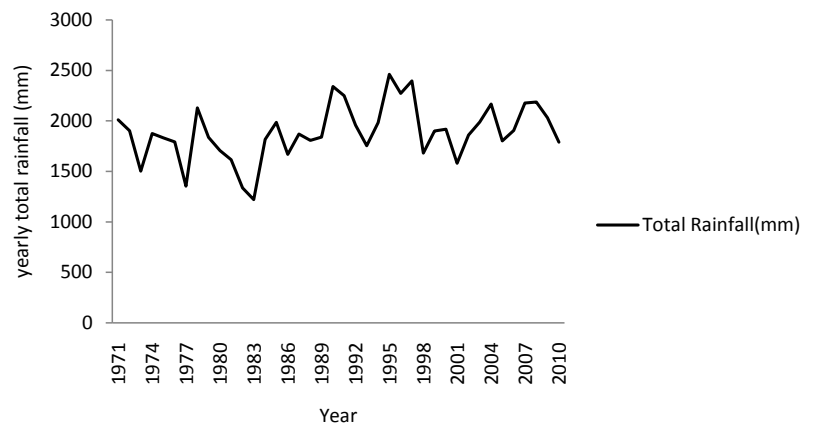

(a)

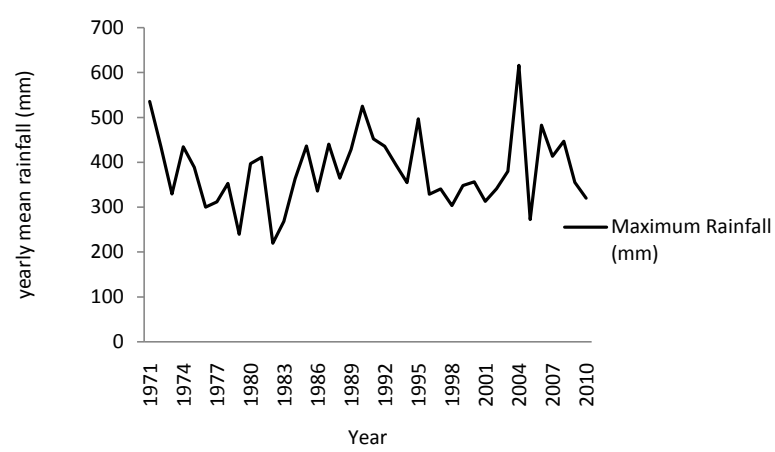

(c)

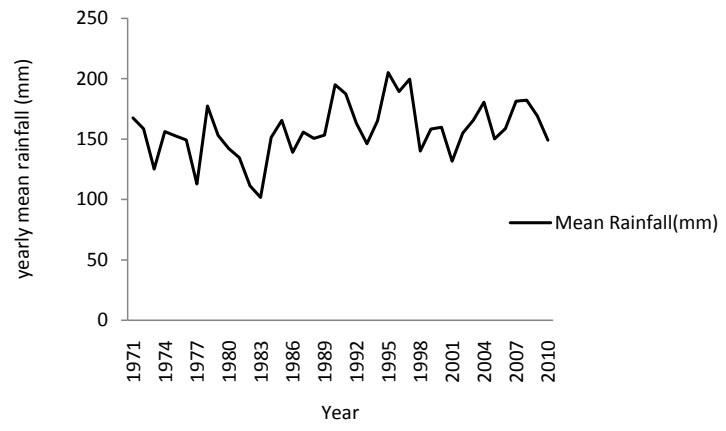

(b)

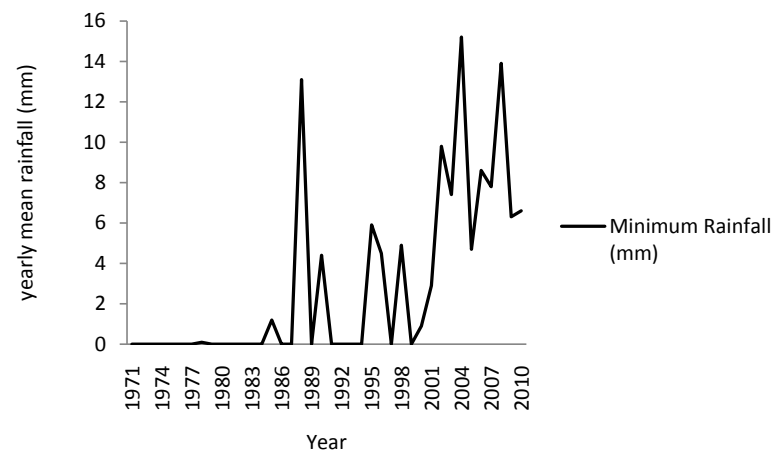

(d)

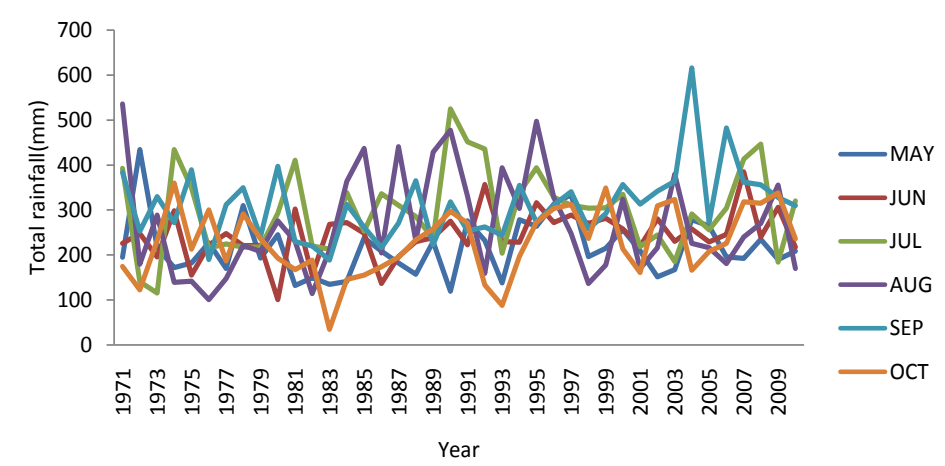

(e)

Figure 4. (a)-(d) Sequence of yearly total rainfall in Onitsha; (e) Sequence of rainfall in the month of May, June, July, August, September and October from 1971 to 2010 in Onitsha. 
Sen's estimator revealed that yearly total rainfalls have trends of $1.437 \mathrm{~mm} /$ year and $-0.023 \mathrm{~mm} /$ year for a period of 1971-1990 and 1991-2010 respectively.

\subsubsection{Sequence Analysis of the Rainfalls}

Figures 5(a)-(d) present sequential values of the rainfalls in Ihiala. The figures apparently show decreasing

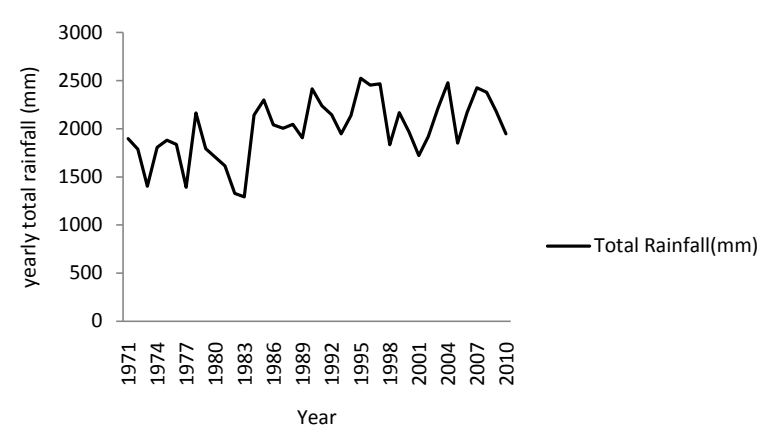

(a)

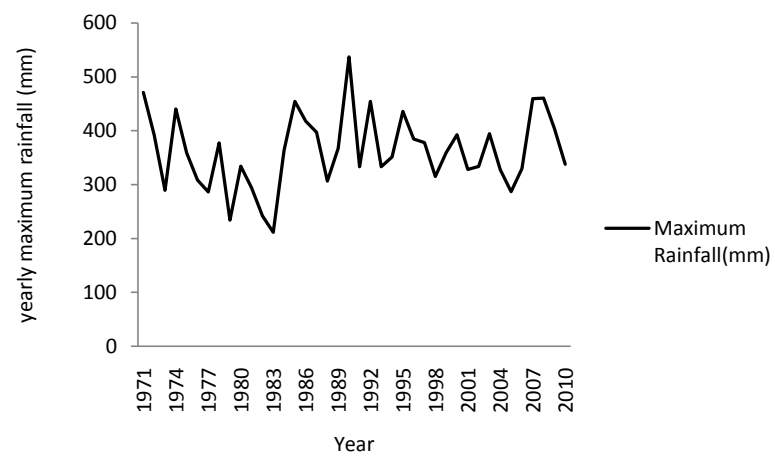

(c)

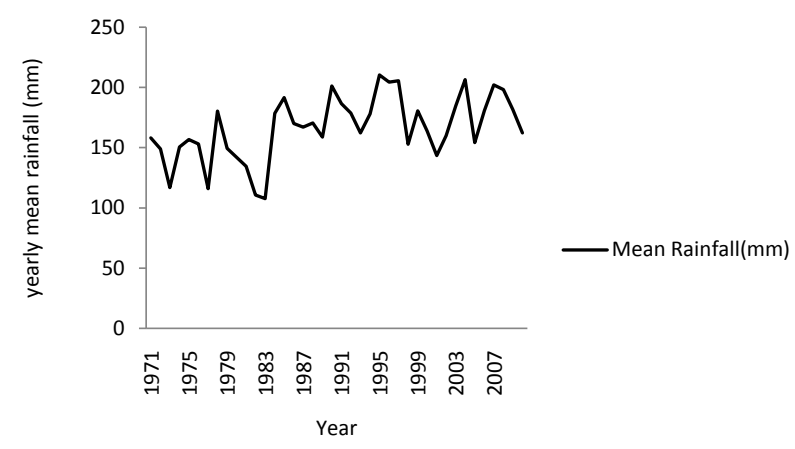

(b)

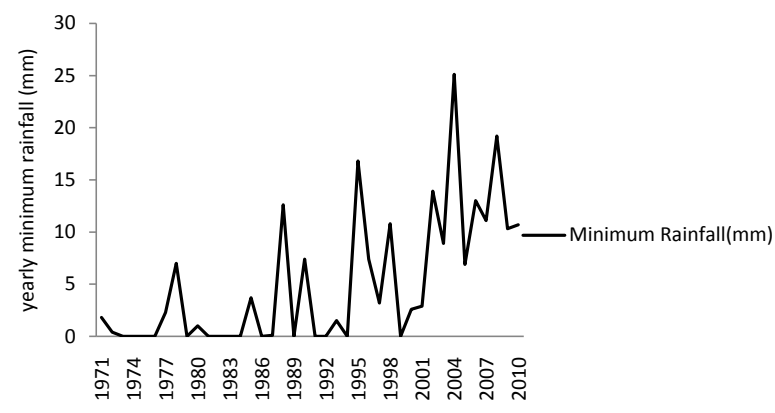

(d)

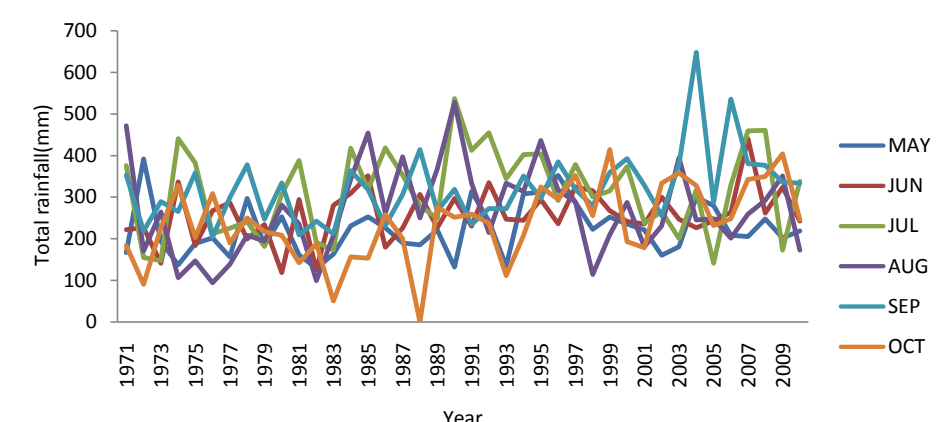

(e)

Figure 5. (a)-(d) Sequence of yearly total rainfall in Ihiala; (e) Sequence of rainfall in the month of May, June, July, August, September and October from 1971 to 2010 in Ihiala.

Table 8. Non-parameter test of summarized statistical data in Ihiala.

\begin{tabular}{|c|c|c|c|c|c|c|c|}
\hline Year & Mean & Mann-Whitney U & Wilcoxon & $Z$-Statistics & $\begin{array}{l}\text { Asymptotic } \\
\text { Significant } \\
\text { (2 Tailed) }\end{array}$ & $\begin{array}{c}\text { Sen's } \\
\text { Estimator }\end{array}$ & $\begin{array}{c}\text { Number of } \\
\text { Samples }\end{array}$ \\
\hline 1971-1980 & 8.8 & \multirow{2}{*}{33} & \multirow{2}{*}{88} & \multirow{2}{*}{-1.285} & \multirow{2}{*}{0.199} & \multirow{2}{*}{1.437} & 10 \\
\hline 1981-1990 & 12.2 & & & & & & 10 \\
\hline 1991-2000 & 11 & \multirow{2}{*}{45} & \multirow{2}{*}{100} & \multirow{2}{*}{-0.378} & \multirow{2}{*}{0.705} & \multirow{2}{*}{-0.0232} & 10 \\
\hline 2001-2010 & 10 & & & & & & 10 \\
\hline
\end{tabular}


trends in rainfalls.

Figures 5(a)-(d) illustrate the downward trends appearance of the yearly total, maximum, minimum and mean rainfall. From the graphs, it appears the strongest decreasing trend occurred between 1973 and 1976 and 1981 and 1984 respectively.

Figure 5(c) clearly shows yearly maximum rainfall from 1971 to 2010 which implies that 1990 and 1971 recorded highest magnitude of rainfall with $536.7 \mathrm{~mm}$ and $470.9 \mathrm{~mm}$ respectively. These trends can be attributed to climate change, which manifest itself in the area as temperature is increasing and reduction in rainfall in the years 1973-1976, 1981-1984, 1986, 1989, 1991 and 1999 as showed in Figure 5(d).

Figure 5(e) clearly shows the month of September in 2004 recorded the highest magnitude of rainfall with $648 \mathrm{~mm}$ followed by the month of September in 2006 with $536 \mathrm{~mm}$ of rainfall amounts. The month of October in 1983 recorded the lowest magnitude of rainfall with $0.5 \mathrm{~mm}$.

\section{Conclusion}

The application of this trend analysis framework revealed an overall downward precipitation trend. Ifite-Ogwari station indicated downward trends between 1971 and 1990 and 1991 and 2010, but Awka, Onitsha and Ihiala showed an upward trend between 1971 and 1990 and a downward trend between 1991 and 2010. However, this decrease was found to be statistically significant at $95 \%$ confidence level at the four stations. The trend revealed that August and October had downward trends.

\section{References}

[1] Osborn, T.J., Hulme, M., Jones, P.D. and Basnett, T.A. (2000) Observed Trends in the Daily Intensity of United Kingdom Precipitation. International Journal Climatology, 20, 347-364. http://dx.doi.org/10.1002/(SICI)1097-0088(20000330)20:4<347::AID-JOC475>3.0.CO;2-C

[2] Ventur, F., Rossi Pisa, P. and Ardizzoni, E. (2002) Temperature and Precipitation Trends in Bologna (Italy) from 1952 to 1999. Atmospheric Research, 61, 203-214. http://dx.doi.org/10.1016/S0169-8095(01)00135-1

[3] Lettenmaier, D.P., Wood, E.F. and Wallis, J.R. (1994) Hydro-Climatological Trends in the Continental United States, 1948-88. Journal of Climate, 7, 586-607. http://dx.doi.org/10.1175/1520-0442(1994)007<0586:HCTITC>2.0.CO;2

[4] Turkes, M. (1996) Spatial and Temporal Analysis of Annual Rainfall Variations in Turkey. International Journal of Climatology, 16, 1057-1076. http://dx.doi.org/10.1002/(SICI)1097-0088(199609)16:9<1057::AID-JOC75>3.0.CO;2-D

[5] Zhang, X., Vincent, L.A., Hogg, W.D. and Nitsoo, A. (2000) Temperature and Precipitation Trends in Canada during the 20th Century. Atmospheric Ocean, 38, 395-429. http://dx.doi.org/10.1080/07055900.2000.9649654

[6] Mosmann, V., Castro, A., Fraile, R., Dessens, J. and Sanchez, J.L. (2004) Detection of Statistically Significant Trends in the Summer Precipitation of Mainland Spain. Journal of Atmospheric, 70, 43-53.

[7] Partal, T. and Kahya, E. (2006) Trend Analysis in Turkish Precipitation Data. Hydrological Processes, 20, $2011-2026$. http://dx.doi.org/10.1002/hyp.5993

[8] National Bureau of Statistics (2011) Annual Abstract of Statistics 2011. 27.

[9] Wikipedia (2014) Anambra State. http://en.wikipedia.org/wiki/Anambra_State

[10] NIMET (2014) 2014 Seasonal Rainfall Prediction (SRP). S \& E Consulting, Scottsdale, 9-15.

[11] Kahya, E. and Kalayci, S. (2004) Trend Analysis of Stream Flow in Turkey. Journal of Hydrology, 289, 128-144. http://dx.doi.org/10.1016/j.jhydrol.2003.11.006

[12] Burn, D.H. and Elnur, M. (2002) Detection of Hydrological Trends and Variability. Journal of Hydrology, 255, 107122. http://dx.doi.org/10.1016/S0022-1694(01)00514-5

[13] Loveday, R. (1980) Statistics. A Second Course in Statistics. 2nd Edition, Cambridge University Press, Cambridge.

[14] Guttman, I., Wilks, S.S. and Hunter, J.S. (1971) Introductory Engineering Statistics. 2nd Edition, John Wiley and Sons Inc, New York.

[15] Sen, P.K. (1968) Estimates of the Regression Coefficient Based on Kendall's Tau. Journal of the American Statistical Association, 63, 1379-1389. http://dx.doi.org/10.1080/01621459.1968.10480934 
Scientific Research Publishing (SCIRP) is one of the largest Open Access journal publishers. It is currently publishing more than 200 open access, online, peer-reviewed journals covering a wide range of academic disciplines. SCIRP serves the worldwide academic communities and contributes to the progress and application of science with its publication.

Other selected journals from SCIRP are listed as below. Submit your manuscript to us via either submit@scirp.org or Online Submission Portal.
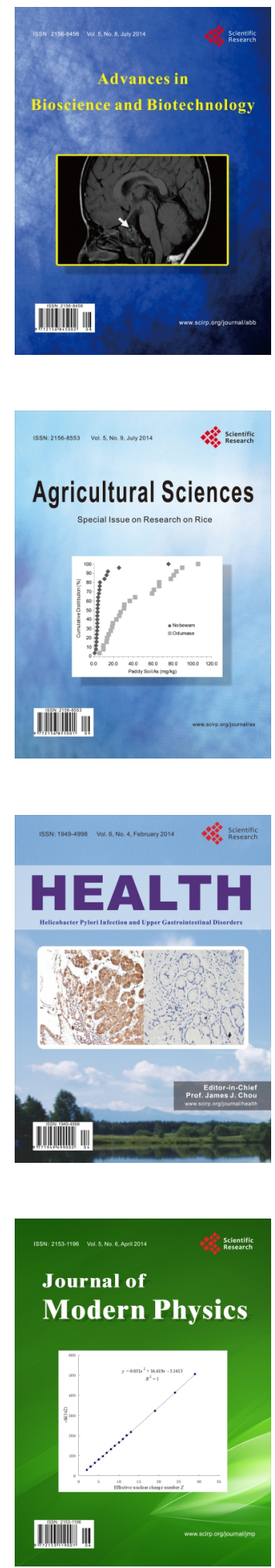
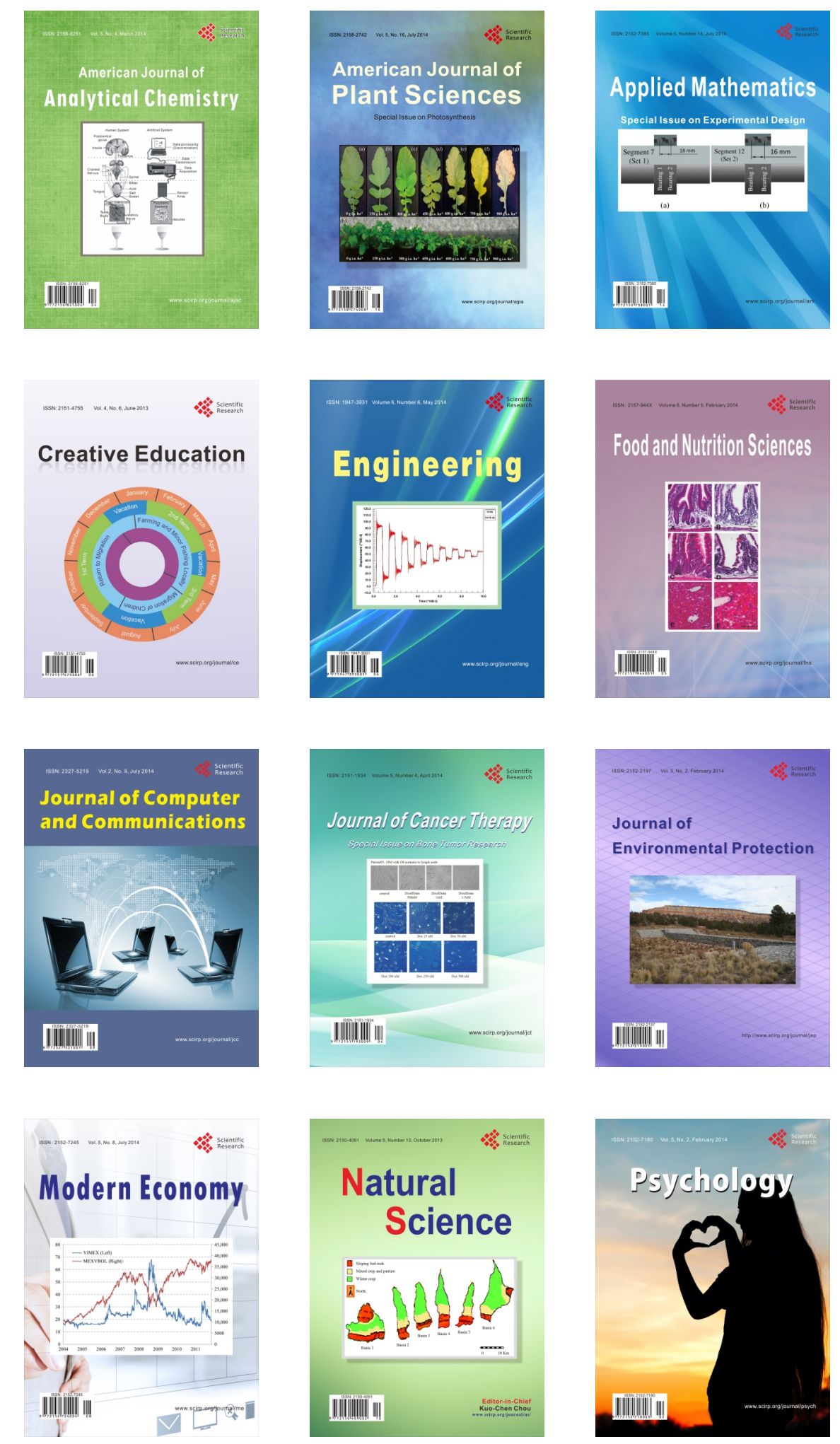